\title{
STUDI STRATEGI PENGEMBANGAN KREDIT PADA USAHA MIKRO,KECIL, DAN MENENGAH OLEH BANK BUMN DI DAERAH CIKARANG-JAWA BARAT KASUS BANK BRI
}

\author{
Hans Adrian \\ Program Studi Magister Managemen Universitas Tarumanagara \\ Silver_claws@ hotmail.co.id
}

\begin{abstract}
Usaha Mikro,Kecil dan Menengah (UMKM) memainkan peran penting dalam pembangunan ekonomi Indonesia sekitar 54-57\% Produk Domestik Bruto Indonesia berasal dari sektor ini. Terlepas dari manfaatnya dalam mengurangi tingkat pengangguran, UMKM juga telah berhasil membuktikan kekuatannya terhadap dampak krisis moneter yang terjadi pada tahun 1998. Cikarang dikenal sebagai salah satu kawasan industri Indonesia sedangkan pelaku bisnis membangun banyak perusahaan besar dan pabrik di sana. Efisiensi organisasi besar ini dalam menjalankan bisnisnya sangat dipengaruhi oleh kemampuan UMKM sebagai pemasok untuk menyediakan bahan yang dibutuhkan, sementara kemampuan UMKM dalam mengelola bisnis mereka bergantung pada masalah permodalan. Oleh karena itu, tesis ini bertujuan untuk menganalisis strategi pengembangan Kredit Usaha Mikro Kecil dan Menengah (UMKM) di daerah Cikarang-Jawa Barat, dan strategi yang dapat diterapkan untuk meningkatkan pertumbuhan dan perkembangan Usaha Mikro Kecil Menengah (UMKM) dengan memanfaatkan bank milik negara sebagai salah satu faktor pertumbuhan ekonomi. Sebagai Agen yang memberikan kontribusi penting bagi perekonomian Indonesia.
\end{abstract}

Keywords : UMKM , Cikarang - Jawa Barat

\section{PENDAHULUAN}

Usaha Mikro,Kecil dan Menengah (UMKM) memainkan peran penting dalam pembangunan ekonomi Indonesia sekitar 54-57\% Produk Domestik Bruto Indonesia berasal dari sektor ini. Terlepas dari manfaatnya dalam mengurangi tingkat pengangguran, UMKM juga telah berhasil membuktikan kekuatannya terhadap dampak krisis moneter yang terjadi pada tahun 1998.

Cikarang dikenal sebagai salah satu kawasan industri Indonesia sedangkan pelaku bisnis membangun banyak perusahaan besar dan pabrik di sana. Efisiensi organisasi besar ini dalam menjalankan bisnisnya sangat dipengaruhi oleh kemampuan UMKM sebagai pemasok untuk menyediakan bahan yang dibutuhkan, sementara kemampuan UMKM dalam mengelola bisnis mereka bergantung pada masalah permodalan. Oleh karena itu, tesis ini bertujuan untuk menganalisis strategi pengembangan Kredit Usaha Mikro Kecil dan Menengah (UMKM) di daerah Cikarang-Jawa Barat, dan strategi yang dapat diterapkan untuk meningkatkan pertumbuhan dan perkembangan Usaha Mikro Kecil Menengah (UMKM) dengan memanfaatkan bank milik negara sebagai salah satu faktor pertumbuhan ekonomi. Sebagai Agen yang memberikan kontribusi penting bagi perekonomian Indonesia.

\section{TELAAH KEPUSTAKAAN}

Secara umum, Strategi hal yang sangat penting dalam dunia bisnis dimana pola aliran dari strategi dapat merupakan kebulatan tekad untuk focus pada tujuan organisasi, langkahlangkah yang ditempuh, dan pengalokasian sumber daya yang diperlukan dalam rangka pencapaian tujuan organisasi.

Pengertian strategi menurut para ahli: 
$>$ Strategi adalah serangkaian keputusan dan tindakan mendasar yang dibuat oleh manajemen puncak dan diimplementasikan oleh seluruh jajaran suatu organisasi dalam rangka pencapaian tujuan organisasi tersebut. (Siagian,2004)

$>$ Strategi yaitu penetapan tujuan dan sasaran dalam jangka panjang (Targeting and long-term goals). (Craig dan Grant)

$>$ Strategi ialah cara untuk mencapai sebuah tujuan berdasarkan analisa terhadap faktor eksternal dan internal. (Syafrizal)

$>$ Strategi merupakan "rencana main" dari suatu perusahaan, yang mencerminkan kesadaran suatu perusahaan mengenai kapan, dimana dan bagaimana ia harus bersaing dalam menghadapi lawan dengan maksud dan tujuan tertentu.(Pearce \& Robinson)

\section{Pengertian Bank}

Pada pasal 1 ayat 2 Undang-undang No 10 tahun 1998 tentang Perubahan UndangUndang Nomor 7 tahun 1992 tentang Perbankan disebutkan bahwa Bank adalah badan usaha yang menghimpun dana dari masyarakat dalam bentuk simpanan dan menyalurkannya kepada masyarakat dalam bentuk kredit dan atau bentuk-bentuk lainnya dalam rangka meningkatkan taraf hidup rakyat banyak.

\section{Fungsi Bank}

Bank sebagai sebuah lembaga keuangan tertentu memiliki fungsi seperti halnya lembaga-lembaga lain. Fungsi bank dalam perekonomian suatu Negara dapat diklasifikasikan sebagai berikut(Irsyad Lubis,2010) :

$>$ Sebagai Agent of Trust

$>$ Sebagai Agent of Develompent

$>$ Sebagai Agent of Service

\section{Kredit}

Pada mulanya istilah kredit berasal dari bahasa Yunani : "credere" yang secara harafiah berarti kepercayaan. Kemudian pada perkembangannya arti kata tersebut semakin berkembang sehingga ada banyak pengertian dari kata kredit tersebut, antara lain :

1. Menurut UU No. 7 tahun 1992 sebagaimana telah diubah menjadi UU No. 10 Tahun 1998 tentang Perbankan adalah disebutkan bahwa kredit adalah penyediaan uang atau tagihan yang dapat dipersamakan dengan itu, berdasarkan persetujuan atau kesepakatan pinjam meminjam antara bank dengan pihak lain yang mewajibkan pihak peminjam untuk melunasi utangnya setelah jangka waktu tertentu dengan memberikan bunga.

2. Kredit adalah kepercayaan/amanat yang diberikan berhubungan dengan kekayaan yang diserahkan atas janji pembayaran kelak, sudah tentu debitur dan kreditur mengadakan permufakatan untuk menyelesaikan transaksi tersebut denga suatu nilai lain misalnya saham atau obligasi.

3. Kredit adalah perkiraan yang tersimpan dalam perkiraan sebuah bank.

4. Kredit merupakan penyediaan uang atau tagihan(yang disamakan dengan uang) berdasarkan kesepakatan pinjam meminjam antara bank dengan pihak lain yang dalam hal ini peminjam berkewajiban melunasi kewajibannya setelah jangka waktu tertentu dengan sejumlah uang yang ditetapkan terdahulu.

\section{Kredit Menurut Tujuan Penggunaannya}

Berdasarkan tujuan penggunaannya kredit dibagi menjadi 2, yaitu (Malayu Hasibuan,2006:89): 
1. Kredit Produktif kredit yang digunakan untuk peningkatan usaha atau produksi atau investasi.Kredit ini diberikan untuk menhasilkan barang dan jasa. Jenis Kredit Produktif, meliputi :

> Kredit investasi, yaitu kredit yang biasanya digunakan untuk keperluan perluasan usaha atau membangun proyek/pabrik baru atau untuk keperluan rehabilitasi.

> Kredit modal kerja, adalah kredit yang digunakan untuk keperluan meningkatkan produksi dalam operasionalnya.

2. Kredit Konsumtif jenis kredit yang digunakan untuk konsumsi secara pribadi. Dalam kredit ini tidak ada pertambahan barang dan jasa yang dihasilkan. Jenisjenis Kredit Konsumtif :

$>$ Kredit Kepemilikan Rumah/KPR

$>$ Kredit Kepemilikan Kendaraan Bermotor

Kredit Kepemilikan Mobil

Kredit Tanpa Agunan

Kartu Kredit

Gambaran umum Perusahaan

Plafond Pinjaman Segmen Kredit Mikro dan Segmen Ritel Komersial di Bank

BRI(Kredit segmen UMKM di Bank BRI)

$>$ Segmen Kredit Mikro di Bank BRI

Produk Kredit Mikro di bank BRI plafond pinjaman 1Jt s/d 200Jt.

Produk Kredit Mikro di Bank BRI, dapat untuk tujuan modal kerja dan investasi, meliputi :

- Kredit Usaha Rakyat Mikro/ KUR Mikro dengan plafond pinjaman 1Jt s/d 25Jt

- Kupedes / Kredit Umum Pedesaan dengan plafond pinjaman 25Jt s/d 200Jt

$>$ Segmen Kredit Ritel Komersial di Bank BRI

Produk Kredit Ritel Komersial di bank BRI plafond pinjaman 200Jt s/d 5Milyar

Produk kredit segmen ritel komersial meliputi :

$>$ Kredit modal kerja, dengan struktur fasilitas :

1. Pinjaman Rekening Koran(CO tetap)

2. Pinjaman berjangka

3. Pinjaman angsuran cicilan tetap(CO menurun)

$>$ Kredit Investasi

Kondisi Pertumbuhan Kredit tahun 2015,2016, dan 2017

Kondisi tahun 2015

-Bank Indonesia (BI) mencatat hingga Desember 2015, kredit yang disalurkan

Perbankan tumbuh meningkat dari 9,5\% (year on year/yoy) menjadi 10,1\% (yoy)

pada Desember 2015.

\section{Kondisi tahun 2016}

-Hingga akhir tahun 2016, kredit perbankan tidak tumbuh seperti yang diharapkan. Secara year to date (tahun kalender Januari-Desember), kredit tumbuh 7,87\%.

\section{Kondisi tahun 2017}

Kredit yang disalurkan perbankan hingga Desember 2017 bertumbuh 8,35\% year on year (yoy). Pertumbuhan intermediasi perbankan juga diikuti dengan tren penurunan suku bunga. Sepanjang tahun 2017.

Strategi Bank BRI saat ini didalam pengembangan Kredit di tahun 2017 
untuk hal ekspansi kredit dilakukan secara lebih selektif terutama untuk nasabah baru yang belum memiliki record di Bank BRI dan lebih mengutamakan nasabah yang sudah memiliki rekening dan biasa memiliki transaksi di Bank BRI. Serta nasabah dari BRI KCP Unit yang ingin naik kelas dari segmen mikro ke segmen ritel komersial, nasabah BRI yang sudah pernah lunas fasilitas pinjamannya. Perubahan strategi yang diberlakukan sejak tahun 2016 dikarenakan tingginya Kredit bermasalah di sektor perbankan secara keseluruhan dari tahun 2015 secara nasional di Indonesia.

Untuk meningkatkan permintaan kredit terutama pada sektor kredit ritel komersial yaitu dengan mendorong Mantri di BRI KCP Unit untuk naik Grade menjadi Account Officer, dimana ditawarkan jenjang karir yang lebih baik. Dengan naik Grade dari mantri menjadi Account Officer secara tidak langsung akan mendorong nasabah dari segmen mikro naik tingkatan ke segmen ritel komersial. Sehingga dengan demikian nasabah segmen mikro yang memiliki potensi untuk naik tingkatan ke segmen ritel komersial.

Sedangkan untuk memperluas dan meningkatkan jumlah nasabah mikro dengan keberadaan Agen Brilink dapat menjadi sarana untuk mempromosikan produk dari Bank BRI sehingga dapat menjangkau ke masyarakat di sekitar lokasi dari Agen Brilink untuk mempermudah nasabah memperoleh layanan perbankan. Sehingga dapat memungkinkan juga untuk memperoleh nasabah baru seperti nasabah produk simpanan serta nasabah pinjaman segmen ritel komersial dan segmen mikro.

\section{METODOLOGI PENELITIAN Rancangan Penelitian}

Penelitian ini menggunakan pendekatan kualitatif. Digunakan pendekatan tersebut disebabkan oleh tipe permasalahan yang dikaji. Dilihat dari segi analisis data, penelitian kualitatif pada dasarnya merupakan penelitian yang menggambarkan isi. Metode yang digunakan untuk kualitatif adalah observasi dan partisipasi.

\section{Lokasi Dan Periode Penelitian}

Penelitian dilaksanakan di PT Bank BRI Tbk, Kantor Cabang Pembantu (KCP) Cikarang (untuk segmen kredit ritel komersial) yang beralamat di Jl. Kapten Sumantri Blok B 9-10, Ruko Cikarang Plaza, Cikarang - Bekasi. Dan di Bank BRI KCP Unit Tegal Danas(untuk segmen kredit mikro) yang beralamat di Jl Raya Tegal Danas Kios B 10-11 RT4/4 (Pasar Tegal Danas), Jayamukti, Cikarang - Bekasi.

Pengambilan data penelitian dilaksanakan pada periode 1 Januari 2015 - 31 Desember 2017.

\section{Sumber dan Metode Pengumpulan Data}

Data-data yang dikumpulkan untuk penelitian ini terdiri dari 2 (dua) sumber yaitu data primer dan data sekunder.

1. Data Primer

Data primer diperoleh melalui wawancara langsung kepada Kepala KCP, Kepala Unit, Mantri Unit, Account Officer KCP serta observasi langsung. Melalui wawancara diajukan pertanyaan mengenai gambaran umum, visi dan misi, strategi untuk expansi kredit.

2. Data sekunder

Data sekunder merupakan kumpulan data yang berisikan informasi yang telah ada dan sebelumnya telah dikumpulkan untuk tujuan yang lain. Data ini biasanya berupa data dokumentasi, arsip-arsip, studi pustaka, buku-buku, artikel dari media cetak maupun internet dan lain sebagainya. Pencarian data sekunder ini bertujuan untuk mendapatkan informasi dan teori-teori yang berhubungan dan mendukung permasalahan yang dibahas, sehingga peneliti dapat memahami permasalahan secara 
lebih mendalam. Data sekunder dalam penelitian ini diperoleh dari studi pustaka, buku-buku, website perusahaan, penelitian terdahulu.

\section{Metode Analisis}

Metode yang digunakan dalam penelitian ini adalah metode deskripsi kualitatif yang focus pada penjelasan objek yang akan diteliti yaitu PT Bank BRI Tbk. KCP Cikarang dan KCP Unit Tegal Danas. Metode ini disesuaikan dengan data fakta dan data pada objek penelitian tanpa pengujian secara kuantitatif.

Analisa ini tidak menggunakan penghitungan matematis penulis hanya melihat dari pengamatan langsung, wawancara dan data laporan perkembangan kredit di Unit kerja Bank BRI yang menjadi tempat penelitian yaitu yaitu PT Bank BRI Tbk. KCP Cikarang dan KCP Unit Tegal Danas periode dari 1/1/2015 s/d 31/12/2017 yaitu pada periode setelah penerapan expansi kredit KCP Cikarang dan KCP Unit Tegal Danas.

Hasil dari pengamatan langsung, wawancara dan data yg telah diperoleh oleh penulis, dituangkan ke dalam penelitian ini mengenai ," Studi Strategi Pengembangan Kredit Pada Usaha Mikro,Kecil, Dan Menengah Oleh Bank BUMN DI Daerah Cikarang-Jawa Barat Kasus BANK BRI.”

\section{Pembahasan Data Pertumbuhan Kredit di Bank BRI KCP Cikarang dan Bank BRI KCP Unit Tegal Danas \\ BRI KCP Cikarang \\ BRI KCP Cikarang periode th 2015}

Pertumbuhan outstanding kredit segmen ritel komersial di th 2015 secara tahunan 19,21025\%

BRI KCP Cikarang periode th 2016

Pertumbuhan outstanding kredit segmen ritel komersial di th 2016 secara tahunan $11,3675 \%$. Hal ini dikarenakan terjadi penurunan kualitas kredit akibat penurunan usaha sehingga dilakukan restrukturisasi kredit. Yang menyebabkan ekspansi kredit melambat.

BRI KCP Cikarang periode th 2017

Pertumbuhan outstanding kredit segmen ritel komersial di th 2017 secara tahunan $14,37908 \%$. Kondisi pertumbuhan kredit masih positif hal ini dikarenakan pemulihan kondisi usaha debitur, meningkatnya permintaan kredit segmen ritel komersial dan beberapa nasabah segmen mikro yang naik kelas ke segmen ritel komersial.

BRI KCP Unit Tegal Danas

-Pertumbuhan outstanding kredit segmen mikro di th 2015 secara tahunan 19,468\%

-Pertumbuhan outstanding kredit segmen mikro di th 2016 secara tahunan 27,65957\%. Hal ini dikarenakan masih tingginya permintaan atas kredit segmen mikro. Walaupun kondisi makro ekonomi yg melambat sektor usaha mikro masih ada pertumbuhan yang positif.

-Pertumbuhan outstanding kredit segmen mikro di th 2017 secara tahunan 13,66689\%. Pertumbuhan kredit segmen mikro melambat dikarenakan beberapa nasabah segmen kredit mikro naik kelas ke segmen ritel komersial sehingga pinjaman di BRI Unit Tegal Danas dilunasi.

\section{Kesimpulan}

Berdasarkan hasil analisis dapat ditarik kesimpulan sebagai berikut : 
- Pada periode tahun 2015, pertumbuhan total Kredit di BRI KCP Cikarang kredit segmen ritel komersial di th 2015 secara tahunan 19,21025\%, KCP Unit Tegal Danas pertumbuhan total kredit segmen mikro di th 2015 secara tahunan 19,468\%. Kredit tetap tumbuh walau pun kondisi ekonomi makro sedang melambat di tahun 2015.

- Pada periode tahun 2016, Pertumbuhan total kredit segmen ritel komersial di BRI KCP Cikarang th 2016 secara tahunan 11,3675\%. Hal ini dikarenakan terjadi penurunan kualitas kredit akibat penurunan usaha sehingga dilakukan restrukturisasi kredit. Yang menyebabkan ekspansi kredit melambat. Sedangkan Pertumbuhan total kredit segmen mikro di BRI KCP Unit Tegal Danas th 2016 secara tahunan 27,65957\%. Hal ini dikarenakan masih tingginya permintaan atas kredit segmen mikro. Walaupun kondisi makro ekonomi yang melambat sektor usaha mikro masih ada pertumbuhan yang positif. Dalam hal ini strategi pemasaran yang dilakukan masih umum seperti staregi pemasaran yang dilakukan oleh perusahaan competitor yaitu dengan cara strategi pemasaran berupa promosi penjualan dan penjualan langsung. Berdasarkan hasil wawancara dengan Kepala KCP dan Kepala Unit Bank BRI diketahui strategi penjualan langsung yang paling efektif dalam meningkatkan pertumbuhan dana simpanan dan outstanding pinjaman adalah : visiting, cold calling, referral dan mengadakan pameran.

- Pada periode tahun 2017 ,pertumbuhan total kredit segmen ritel komersial di KCP Cikarang th 2017 secara tahunan 14,37908\%. Kondisi pertumbuhan kredit masih positif hal ini dikarenakan pemulihan kondisi usaha debitur, meningkatnya permintaan kredit segmen ritel komersial dan beberapa nasabah segmen mikro yang naik kelas ke segmen ritel komersial. Pertumbuhan total kredit segmen mikro di BRI KCP Unit Tegal Danas th 2017 secara tahunan 13,66689\%. Pertumbuhan kredit segmen mikro melambat dikarenakan beberapa nasabah segmen kredit mikro naik kelas ke segmen ritel komersial sehingga pinjaman di BRI Unit Tegal Danas dilunasi. Dalam hal ini penerapan strategi untuk menaik kelaskan nasabah segmen mikro ke segmen ritel komersial sudah dijalankan dari awal th 2017 dengan cara Mantri BRI Unit naik Grade ke Account Officer. Sehingga nasabah mikro dapat didorong untuk naik kelas. Dengan diberlakukannya strategi ini di awal 2017 untuk mendorong nasabah mikro untuk naik kelas ke segmen ritel komersial melalui merekrut Account officer baru dari pihak internal BRI melalui Mantri BRI Unit maka Bank BRI dapat tetap konsisten untuk menjaga pertumbuhan kredit segmen ritel komersial, disaat perlambatan pertumbuhan kredit secara nasional. Selain merekrut Account Officer dari Mantri BRI Unit, dikarenakan untuk memenuhi kebutuhan rencana bisnis pegawai dari internal BRI dari bagian support yang pindah bagian ke Account Officer untuk memenuhi kebutuhan target bisnis yang sudah ditetapkan oleh perusahaan. Hal ini dikarenakan orang internal BRI yang sudah menjadi pegawai sudah memahami budaya kerja dibandingkan dengan merekrut orang external yang memerlukan biaya untuk iklan. Sedangkan untuk segmen kredit mikro dengan adanya Agen Brilink yang berlokasi pada tempat-tempat yang tidak ada unit kerja BRI maka nasabah tetap dapat melakukan transaksi perbankan walaupun tidak datang ke unit kerja BRI. Selain itu dengan adanya Agen Brilink akan dapat menjadi sarana untuk mempromosikan BRI untuk memperoleh nasabah baru untuk bentuk simpanan dan juga untuk pinjaman berupa kredit segmen mikro dan segmen ritel komersial. Serta meningkatkan brand image dari BRI itu sendiri. 


\section{Saran}

Saran yang dapat diberikan setelah dilakukannya penelitian ini adalah :

1. Bank BRI KCP Cikarang dan Bank BRI KCP Unit Tegal Danas agar selalu melakukan sinergi dengan KCP dan Unit yang saling berdekatan agar nasabahnasabah yang dianggap potensial dapat semuanya tergarap, baik dari segmen ritel komersial dan segmen mikro.

2. Proses pengajuan pinjaman baik dari segmen ritel komersial dan segmen mikro dapat dipercepat dikarenakan semakin ketatnya persaingan di segmen pembiayaan UMKM di daerah Cikarang-Jawa Barat. Namun tetap berpegang teguh pada prinsip kehatihatian.

3. Dalam persaingan antar bank, sebaiknya pihak manajemen pelakukan perbandingan penawaran suku bunga antar bank dengan plafond sejenis. Tidak hanya berfokus kepada pinjaman tinggi, namun juga tetap memperhatikan debitur / nasabah dengan plafond pinjaman dibawah Rp. 1 Milyar.

4. Bank BRI tetap selalu berkomitmen untuk melayani para pengusaha UMKM dikarenakan UMKM adalah sector usaha yang sangat vital dalam menggerakkan roda perekonomian Indonesia.

\section{DAFTAR PUSTAKA}

Abdullan. (2001). Analisis Kinerja bank. Jakarta : Rineka Cipta.

Assauri,S. (2009). Manajemen Pemasaran. Penerbit Grafindo Persada, Jakarta.

Dendawijaya,Lukman. (2009). Manajemen Perbankan. Ghalia Indonesia : Jakarta.

Kasmir. (2014). Bank dan Lembaga Keuangan Lainnya. PT Raja Grafindo Persada, Jakarta.

Kotler,P (2003). Manajemen Pemasaran, Jilit I dan II. Jakarta : PT. Indeks Kelompok

Gramedia.

Kuncoro, Mudrajad dan Suharjono. (2002). Manajemen Perbankan; teori dan aplikasi, Edisi pertama, BPFE, Yogyakarta.

Undang-Undang Tentang Perbankan, No.10, 1998

Undang-Undang Tentang Perbankan, No.7, 1992

Budi Untung. (2000) Kredit Perbankan di Indonesia. Yogyakarta : Penerbit Andi.

Rivai, Veithzal, Andria Permata Veithzal, dan Ferry N Idroes; Bank dan Financial Institution Management, Rajawali Pers, Jakarta : 2007

Sugiono, Dr, Prof.(2010). Metode Penelitian Kuantitatif Kualitatif Dan R\&D, Alfabeta, Bandung.

Usman, Rachmadi.(2003). Aspek-aspek Hukum Perbankan di Indonesia. Jakarta: Gramedia Pustaka Utama.

Wibowo, Singgih,dkk.(2002). Pedoman Mengelola Perusahaan Kecil. Jakarta: Penebar Swadaya.

Nasution, Mustafa Edwin \& Usman, Hardius(2006). Proses Penelitian Kualitatif. Jakarta :

Lembaga Penerbit Fakultas Ekonomi Universitas Indonesia.

Supramono, Gatot.(2009). Perbankan dan Masalah Kredit. Jakarta : Penerbit Rineka Cipta. Lexy, Moleong, Metodologi Penelitian Kualitatif, Bandung: PT. Remaja Rosdakarya, 2005, hal 103.

\section{Website :}

www.bi.go.id

www.depkop.go.id

bri.co.id 
